\title{
Teoria da Percepção no Behaviorismo Radical ${ }^{1}$
}

\author{
Carlos Eduardo Lopes ${ }^{2}$ \\ José Antônio Damásio Abib \\ Universidade Federal de São Carlos
}

\begin{abstract}
RESUMO: A percepção é explicada por Skinner através do conceito de comportamento perceptivo - um comportamento complexo que se inter-relaciona com muitos outros. O estudo da percepção na teoria skinneriana pode ser dividido em duas etapas: estudo do comportamento perceptivo como precorrente e estudo dos precorrentes do comportamento perceptivo. No primeiro caso, a investigação passa pelo processo de resolução de problemas, no qual o comportamento perceptivo desempenha um papel fundamental modificando o ambiente, o que permite a emissão do comportamento discriminativo e a solução do problema. No segundo caso, a investigação trata com uma série de outros comportamentos, tais como, propósito, atenção, e consciência, que modificam a probabilidade de emissão do comportamento perceptivo. A análise das relações entre o comportamento perceptivo e demais comportamentos culmina no esboço de uma teoria da percepção no behaviorismo radical, que é mais convincente do que explicações mentalistas que fazem uso da "teoria da cópia".
\end{abstract}

Palavras-chave: percepção; behaviorismo radical; comportamento perceptivo; encadeamento; auto-estimulação.

\section{Radical Behaviorism's Theory of Perception}

\begin{abstract}
Perception is explained by Skinner by means of the concept of perceptive behavior - a complex behavior which is interrelated with many others. The study of perception in Skinner's theory can be divided into two stages: the study of perceptive behavior as precurrent and the study of the precurrent of perceptive behavior. In the first case, the investigation undergoes the process of solving problems, in which perceptive behavior plays a fundamental role modifying the environment, which to allow the emission of discriminative behavior and the solution of problem. In the second case, the investigation deals with a series of others behaviors, such as purpose, attention, and conscience, which modifies the probability of emission of perceptive behavior. The analysis of the relations between perceptive behavior and others behaviors, results in an outline of a theory of perception in radical behaviorism, which is more convincing than mentalistic explanation which make use of the "theory of the copy".
\end{abstract}

Key words: perception; radical behaviorism; perceptive behavior; chaining; self-stimulation.

Em explicações mentalistas a percepção é freqüentemente considerada o ponto de contato entre o mundo físico e o da mente, sendo, por esse motivo, um processo psicofísico: um estímulo físico excita, por exemplo, os receptores do olho, essa excitação é convertida em impulsos elétricos, que percorrem vias nervosas até chegar ao cérebro, onde provocam uma mudança estrutural (chamada "engrama") da área do córtex (que recebe o impulso) - até aqui todo o processo é físico. De alguma maneira o engrama é convertido em uma cópia mental do objeto, chamada "experiência", "idéia" ou "representação", que por sua vez é "percebida" pela consciência (considerada por essas teorias como um órgão interno de percepção) - essa é a parte mental da percepção.

Atualmente não é difícil identificar traços ou conseqüências desse dualismo. Expressões como "isso está só na sua imaginação" são freqüentemente interpretadas, por teóricos, como uma descrição de um "mundo especial" para as

1 Trabalho apresentado junto ao Departamento de Psicologia da Universidade Federal de São Carlos como monografia para conclusão do curso de bacharelado em psicologia.

2 Endereço: Departamento de Filosofia e Metodologia das Ciências da Universidade Federal de São Carlos. Rodovia Washington Luís (SP 310), Km 235, CEP 13565-905, São Carlos - SP.

E-mail: caelopes@terra.com.br cópias fabricadas nas percepções passadas. Direta ou indiretamente, atualmente a grande maioria das explicações psicológicas da percepção acabam fazendo uso das "cópias mentais".

Mas o que é possível dizer a respeito de uma explicação comportamental, como a do behaviorismo radical de Skinner (1957, 1961, 1966, 1968, 1969, 1982)? Essa explicação não poderia fazer uso de "cópias" uma vez que não admite a existência de um "mundo mental" de natureza especial. O presente artigo trata dessa explicação e tem o intuito de verificar se ela é coerente e convincente. Essa tarefa consiste não somente na análise isolada do tema da percepção, mas também no estudo de alguns dos tópicos que se relacionam com esse tema, como, por exemplo, autoconhecimento, propósito, pensamento, resolução de problemas. O número de relações entre a percepção e outros temas é uma prova da importância de um estudo dessa natureza no behaviorismo radical e na ciência do comportamento.

Esse texto trata, portanto, de uma revisão conceitual do comportamento perceptivo conforme os preceitos do behaviorismo radical, analisando suas relações funcionais com os demais comportamentos humanos. Em última análise, pretende-se esboçar uma teoria da percepção no behaviorismo radical, apontando suas vantagens em relação às concepções mentalistas da percepção. 


\section{Teoria da Cópia}

Tradicionalmente considera-se a percepção como o processo pelo qual entramos em contato com a realidade; entretanto, é explicada através da idéia de uma "cópia mental" do mundo percebido. Quando percebemos alguma coisa, "fabricamos" uma cópia mental do objeto, essa cópia é armazenada na memória e posteriormente pode vir a ser usada, no caso de uma rememoração. Esse modo de explicar a percepção é conhecido pelo nome de "teoria da cópia" ou "teoria da representação mental" (Skinner, 1945/1961, 1953/ 1966, 1957, 1968, 1969, 1974).

No que diz respeito ao papel do sujeito na percepção, existem basicamente duas possibilidades: o sujeito como "percebedor", um sujeito que "captura" percepções no sentido de "tomar posse delas". Como já foi mencionado anteriormente, para essa tradição, a percepção consiste de um processo psicofísico. De acordo com essa proposta, toda a percepção tem como resultado uma cópia do ambiente (experiência, idéia ou representação). Isso obriga, muitas vezes, os defensores dessa concepção a aceitar a existência de uma realidade em si, que nunca pode ser diretamente acessada. Mas qual seria a função de tal realidade? Se nunca acessamos a "verdadeira realidade", é possível defender que ela não passa de uma inferência ou até mesmo que sequer existe. Outra possibilidade é considerar o sujeito como "recebedor de percepções", essa interpretação da percepção passa pelas propostas de Pavlov (1927/1960), Watson (1924/ 1930) e de alguns cognitivistas contemporâneos (Turing, 1950/1996), nas quais o sujeito tem um papel mais passivo, sendo estimulado (recebendo estímulos) pelo ambiente. Portanto, a realidade deixa de ser questionada, passando a existir independentemente do indivíduo que a percebe. Apenas no caso do cognitivismo, o mundo da experiência continua resguardado como função explicativa. A percepção começa no ambiente (realidade), mas a cópia mental continua sendo usada como meio de explicação. Por exemplo, em modelos computacionais da mente, nos quais o ambiente fornece um input e o organismo reage com um output, e entre esses dois eventos ocorrem processos cognitivos que são fundamentais, nessa perspectiva, para explicar a ação (Skinner, 1969, 1977/1982).

As duas posições acima mencionadas levantam o problema da experiência versus realidade. Na história da psicologia científica tentou-se resolver esse problema estudando-se a experiência imediata através da introspecção-experimental com o objetivo de demonstrar no laboratório que a experiência subjetiva é diferente da realidade objetiva, chegando-se assim aos elementos "puros da experiência" (Köhler, 1929/1970). Essa tentativa fracassou, e o programa da psicologia da Gestalt representou um novo esforço para estudar a experiência imediata, onde se reformulou os conceitos de "experiência", "introspecção" e "realidade". Não é possível, no entanto, nem é nosso objetivo examinar, aqui, esse programa.

A proposta de Skinner $(1969,1974)$ para a questão experiência versus realidade baseia-se na noção de contingên- cias de reforço. A única coisa que existe são as relações funcionais entre o comportamento do indivíduo e o ambiente, sendo que o conceito de ambiente não se refere apenas ao cenário atual - ao estímulo antecedente -, mas sim a tudo que afeta o indivíduo, como, por exemplo, sua história passada de reforçamento e punição. De modo geral, não há nada além das contingências, cada indivíduo tem sua própria experiência (realidade), embora não se deva entendê-la como uma cópia privada do ambiente; ela refere-se às contingências, às quais o indivíduo foi e está sendo exposto durante sua vida. ${ }^{3}$

Em resumo, as dicotomias "experiência versus realidade", "percebedor versus recebedor" não se aplicam às concepções de Skinner; em primeiro lugar, porque as "cópias mentais" não são usadas nessa explicação e em segundo porque não há uma separação a priori do estímulo e da resposta, a relação entre eles (contingência) é o dado inicial, não sendo possível separar um do outro (não há estímulo sem resposta e muito menos resposta sem estímulo). A única coisa que deve ser levada em consideração são os comportamentos envolvidos e as variáveis das quais eles são função.

\section{O Comportamento Perceptivo ${ }^{4}$}

Uma explicação comportamental da percepção, com base no behaviorismo radical de Skinner (1953/1966, 1968, 1969, 1974), tem várias vantagens sobre o uso da teoria da cópia. Quando se faz uso de uma cópia mental para explicar a percepção, ao invés de elucidá-la, cria-se mais perguntas a serem respondidas. Supondo que algum pesquisador encontre uma cópia do mundo, seja lá o que ela for ou onde possa estar, ainda assim restaria descobrir como isso se transforma em percepção; seguindo a lógica que norteia a teoria da cópia, a percepção só poderia ocorrer se houvesse uma cópia dessa cópia, e assim ad infinitum. Em contrapartida, quando se explica a percepção em termos de comportamento perceptivo, não se necessita de mais nenhuma cópia, ou de outra mediação mental, a identificação das variáveis que podem controlar esse comportamento é prova de que a percepção é mais uma questão de controle de estímulos do que de uma cópia mental.

Antes de iniciar a discussão, propriamente dita, desse comportamento, vale ressaltar mais um ponto. No estudo da percepção, a visão é sem sombra de dúvida o sentido que mais se destaca (no ser humano ela parece ser, normalmente, o sentido mais complexo e mais desenvolvido), uma prova disto é a própria teoria da cópia, que não é usada, geralmente, para explicar nenhum outro sentido além da visão.

3 Nesse sentido a experiência do indivíduo é a sua realidade e, sendo assim, os termos experiência e realidade adquirem, na teoria de Skinner, praticamente o mesmo significado.

4 Skinner (1968), no livro The Technology of Teaching, usa o termo comportamento perceptual, ao invés de comportamento perceptivo. 
Esse é o primeiro motivo pelo qual a visão será abordada prioritariamente nesse texto. Além disso, existe o fato de que a visão relaciona-se com os outros sentidos (quando vemos uma superfície áspera, não é preciso, na maioria das vezes, passar a mão sobre ela para saber qual é sua textura). Entretanto, todos os sentidos podem ser tratados da mesma forma e com o mesmo grau de importância. Sendo assim, no decorrer do texto, quando se estiver falando da visão é possível, na maioria das vezes, substituí-la por qualquer outro sentido (audição, olfato, etc.).

\section{Comportamento de Ver $^{5}$}

Considerando-se que o aparato fisiológico não apresente nenhum problema, ver é um comportamento respondente. No decorrer da vida do indivíduo a resposta visual incondicionada "pura", vai recebendo, cada vez mais, influência do condicionamento. Sendo assim, estímulos anteriormente tidos como neutros, com o passar do tempo, através do pareamento com o estímulo eliciador, biologicamente mais forte, passam a eliciar a resposta visual - tornam-se estímulos condicionados para esse resposta.

A visão incondicionada pode ser traduzida da seguinte forma: na presença do estímulo visual $\mathrm{X}$ a resposta de ver $\mathrm{X}$ é eliciada (embora esse tipo de visão seja praticamente impossível de ocorrer isoladamente; na maioria das vezes existe pareamento com outros estímulos). Já a visão condicionada ocorreria quando na presença de um estímulo visual, ou não-visual, diferente de $\mathrm{X}$, previamente pareado com o estímulo visual $\mathrm{X}$, a resposta de ver $\mathrm{X}$ é eliciada.

Existe ainda, na visão condicionada, um outro fato, apontado por Skinner (1953/1966): "estímulos que geram visão condicionada muitas vezes são reforçadores por fazer isso" (p. 270). Isso se deve ao fato de que a visão de determinado objeto é, em alguns casos, reforçadora, o que torna os estímulos que a eliciam reforçadores condicionados. Um exemplo comum desse tipo de visão ocorre quando nos deparamos com obras de arte que nos fazem lembrar de eventos passados agradáveis (reforçadores). Nesse caso, os estímulos oriundos dessas obras passam a ter função de reforçadores condicionados, aumentando a freqüência com que nos expomos a eles.

Outro tipo de visão é a operante, na qual um comportamento visual é tão forte que passa a ser emitido na ausência da estimulação visual específica. De acordo com o esquema anterior, é possível explicar esse tipo de visão da seguinte forma: um comportamento $\mathrm{P}$ produz a estimulação visual $\mathrm{X}$, que, por sua vez, elicia uma resposta visual, ver X. A freqüência do comportamento $\mathrm{P}$ é um indicador de que o comportamento de ver $\mathrm{X}$ é de algum modo reforçador (ver $X$ funciona como reforçador condicionado), podendo-se chegar a um ponto em que a resposta de ver $\mathrm{X}$ ocorre mesmo na

5 O comportamento de ver é um dos principais representantes do chamado comportamento perceptivo, um comportamento complexo que, como será apresentado no decorrer do texto, relaciona-se com praticamente todos os demais comportamentos. ausência do estímulo visual X (Skinner, 1953/1966, 1968). Dessa forma, a resposta visual passa a ser emitida ao invés de ser eliciada.

A visão operante é controlada basicamente por duas variáveis, as operações estabelecedoras (privação e estimulação aversiva) e o reforço operante. Sendo assim, a mudança do nível de privação, por exemplo, propicia uma maior ou menor probabilidade de ocorrência da visão operante. Um exemplo pode tornar esse tipo de visão mais claro, um homem que está privado de contato sexual tem uma maior probabilidade de emitir respostas que no passado foram reforçadas com contato sexual e também de ver objetos ou cenas eróticas onde não existe nada que sequer lembre essas coisas (ou seja, emitir a resposta de ver onde não houver estímulos relevantes); em outras palavras, qualquer resposta que o "aproxime" de sexo será emitida, como ir a lugares onde ele possa encontrar material erótico, "pensar" em sexo e até mesmo sonhar com sexo, embora, aparentemente, o nível de privação não se altere com isso.

Existem outros exemplos de visão operante que são mais difíceis de explicar. Isso ocorre quando o "ver" é reforçador, ou seja, os estímulos produzidos pela resposta visual têm função de reforçadores, mas a conexão dessa visão com reforçadores primários é indireta e muito remota na história do indivíduo. Por exemplo, o indivíduo que "gosta" de carros antigos empenha-se em ver carros antigos indo a exposições, feiras e outros locais onde poderá vê-los. Ele poderá também ver carros antigos, se isso for suficientemente reforçador, na ausência de qualquer estímulo visual, como de olhos fechados ou em quarto escuro, ou seja, ele pode emitir a resposta visual (visão operante) sem que haja estimulação visual específica. Em um exemplo como esse a tarefa mais difícil seria identificar porque carros antigos tornaram-se reforçadores para esse indivíduo.

A visão operante, portanto, consiste em ver $\mathrm{X}$ na ausência de estímulos relevantes, quando privado da visão de $\mathrm{X}$ ou, se ver $\mathrm{X}$ for suficientemente reforçador para que o indivíduo emita a resposta sem que haja uma estimulação relevante. Existe ainda a possibilidade de que a visão de X, não seja diretamente reforçadora, mas tenha função de comportamento precorrente, possibilitando a emissão de uma resposta subseqüente, essa ocorrência da visão operante será tratada adiante com mais detalhes.

\section{Ver na Ausência do Objeto Visto}

Uma das principais conseqüências do uso da teoria da cópia é a criação do conceito de mente como um depósito de representações elaboradas nas percepções passadas como não há espaço no corpo físico para as cópias (até hoje ninguém descobriu cópias do mundo no sistema nervoso ou em qualquer outra parte do corpo), criou-se um "lugar" especial para elas - a mente -, entretanto, o problema só foi adiado, podendo-se ainda assim interrogar, qual é o lugar da mente?

Uma explicação tradicional de como é possível ver um objeto em sua ausência recorre ao conceito de mente como 
um "lugar" onde estão armazenadas as cópias do mundo. A mente fabricaria e armazenaria uma cópia do objeto percebido, que poderia ser consultada mais tarde se houvesse necessidade, mesmo na ausência do "objeto real". Portanto, se for possível explicar a visão na ausência do objeto sem que, para isso, usemos uma cópia mental, além de abandonar a teoria da cópia abandonaremos também o conceito de "representação" na teoria da percepção.

Skinner (1953/1966) apresenta duas explicações para o "ver na ausência do objeto visto" condicionada, que ocorre através de condicionamento clássico, um estímulo originalmente neutro passa a eliciar a resposta devido ao pareamento com o estímulo eliciador - ao esperar o jantar, a presença de talheres, por exemplo, pode ser suficiente para que o sujeito veja comida antes mesmo que ela seja servida. Em segundo lugar, com a visão operante, que ocorre quando a visão de determinado objeto for suficientemente reforçadora para que a resposta visual passe a ser emitida ao invés de eliciada - a resposta visual torna-se independente do estímulo antecedente.

Quanto maior a exposição ao pareamento entre estímulos não visuais e estímulos visuais, maior será a probabilidade da pessoa adquirir um repertório visual sob controle de estímulos não visuais, tanto no caso da visão condicionada como no da operante. Uma prova disso é dada quando se compara uma pessoa que lê muito com uma pessoa que lê pouco e vê televisão com freqüência. A pessoa que tem por hábito a leitura, à medida que lê consegue ver as cenas descritas no texto, enquanto a outra pessoa tem uma certa dificuldade para conseguir fazer isso; uma possível explicação é que o leitor assíduo adquiriu um repertório visual sob controle de estímulos verbais, enquanto a outra pessoa tem grande parte de seu repertório visual controlado apenas por estímulos visuais.

Muitas vezes é difícil separar cada um dos tipos de visão sendo que o que ocorre na maioria das vezes parece ser um misto de controle que inclui variáveis emocionais e motivacionais, mas em todos os casos verifica-se que o controle por estímulos, ao invés de "cópias", é a chave para explicar o que usualmente é chamado de "imagens mentais".

\section{Comportamento Perceptivo Precorrente: Resolução de Problemas}

Ampliando-se o conceito de percepção a ponto de abranger os eventos privados do indivíduo chegaremos à conclu-

6 Skinner $(1945 / 1961,1968)$ também trata o "ver na ausência do objeto visto" como comportamento perceptivo encoberto.

7 É possível que variáveis filogenéticas tenham alguma importância para o "ver na ausência do objeto visto": "não é de surpreender que, ao ver um pássaro voar para trás de um tronco de uma árvore, nos comportamos como se ele continuasse a existir fora do alcance de nossa visão" (Skinner, 1974, p. 76). Nesse caso, o pássaro continua a existir (ou continuamos a vê-lo), mesmo quando não estamos diante dele, o que, provavelmente, foi vantajoso para a espécie durante a caça. Entretanto, não parece ser muito seguro afirmar que esse tipo de visão tem origem filogenética, bastando lembrar a discussão, que tem origem em Piaget, sobre a "permanência de objeto". são de que a percepção pode ser considerada um dos principais comportamentos precorrentes através do qual construímos nossa realidade ${ }^{8}$. Em outras palavras, o comportamento perceptivo muitas vezes não recebe conseqüências reforçadoras imediatas, mas é indispensável para a emissão de uma resposta subseqüente que tem conseqüência reforçadora.

A visão operante pode desempenhar o papel de comportamento precorrente, o ver não é diretamente reforçado, mas os estímulos produzidos por essa resposta têm função discriminativa, o que propicia a execução de um comportamento subseqüente que tem alta probabilidade de ser reforçado. Um exemplo disso ocorre quando um sujeito resolve um problema visualmente na ausência de estímulos visuais9. A produção de estímulos visuais pode facilitar a resolução do problema, sendo assim, a pessoa que tem dificuldade em apresentar esse tipo de visão, também terá maior dificuldade em chegar à solução do problema. Dessa maneira, é possível afirmar que a visão, enquanto comportamento precorrente, está intimamente ligada ao processo de resolução de problemas.

Ter um problema significa estar diante de uma situação em que uma resposta apresenta uma certa probabilidade de ser emitida, mas por falta de uma estimulação discriminativa adequada isso não pode ocorrer (Skinner, 1953/1966, 1969). Portanto, o processo de resolução de problemas pode ser considerado como constituído, basicamente, por respostas manipulativas e discriminativas: diante de um problema manipulamos variáveis a fim de produzir estímulos discriminativos que permitam a emissão das respostas discriminativa e consumatória (Skinner, 1968). Muitas vezes as respostas manipulativas são respostas visuais que têm como produto estímulos que podem adquirir função discriminativa, permitindo a resolução mais rápida do problema em questão. Desse modo, um indivíduo, ao descrever como resolveu um problema pode remeter essa descrição à produção de estímulos discriminativos visuais. Um exemplo disso é dado por Skinner (1953/1966):

Pense em um cubo, com todas as superficies pintadas de vermelho. Divida o cubo em vinte e sete cubos iguais fazendo cortes, dois cortes horizontais e dois conjuntos de cortes verticais. Quantos dos cubos resultantes terão três faces pintadas de vermelho, quantos terão duas, quantos terão uma e quantos não terão nenhuma? (p. 273).

Quando perguntado como resolveu esse problema, o sujeito pode dizer que viu o cubo maior, pintou suas faces de vermelho, fez os cortes, separou os cubos resultantes e contou as faces vermelhas de cada um. Nesse caso, a capacidade de emitir uma resposta visual foi claramente necessária para a resolução do problema, embora, essa não seja a única maneira de resolvê-lo.

8 Cf. a discussão sobre a dicotomia "experiência versus realidade" no tópico "Teoria da Cópia".

9 Nesse caso, não é o ver que é reforçador, mas sim a solução do problema, que acaba por reforçar, de maneira diferencial, toda a cadeia de comportamentos que tornou possível a solução (inclusive o "ver"). 
A "teoria da cópia" também apresenta uma explicação para a resolução visual de problemas. Quando, por exemplo, precisamos ensinar alguém a chegar a um lugar que não conhece, podemos ver o lugar em questão e ensinar com base nessa visão. Esse fato é explicado pelos defensores da representação mental com uma cópia mental do caminho que foi armazenada anteriormente em nossa mente. Enquanto nesse tipo de explicação estamos vendo o que vimos, na explicação skinneriana estamos vendo como vimos (Skinner, 1974), ou seja, para explicar a visão, tanto na presença quanto na ausência do objeto, é a resposta de ver que deve ser empregada e não uma cópia mental fabricada no ato da percepção e depois "re-vista".

\section{Precorrentes do Comportamento Perceptivo: Propósito e Atenção}

Tradicionalmente quando se diz que determinado comportamento é intencional a questão volta-se ao propósito do indivíduo, que as teorias mentalistas consideram como cau$s a$ do comportamento -"o propósito do jogador é vencer", nesse sentido propósito é entendido como uma causa final, um objetivo a ser atingido que controla o comportamento que tem a intenção ${ }^{10}$ de atingir esse objetivo. É claro que falta explicar o que mantém um comportamento dirigido a uma conseqüência futura que pode nunca ter ocorrido.

No behaviorismo radical o propósito e a intenção são interpretados como uma conseqüência reforçadora - a pessoa comporta-se de determinada maneira porque é reforçada por fazer isso -, o propósito nesse sentido é a causa do comportamento, embora não se trate de causalidade final. $\mathrm{O}$ mesmo pode ser dito em relação ao comportamento de ver: "nós tendemos a agir para produzir estímulos que são reforçadores quando vistos." (Skinner, 1974, p. 82).

A relação entre o propósito e o comportamento perceptivo pode ser encontrada na análise dos precorrentes desse comportamento. "Olhar na direção de..." muitas vezes é confundido com o comportamento de ver, mas "olhar em direção da multidão" é um comportamento público, enquanto que a resposta de vê-la é privada. Uma vez que o sistema visual é único para qualquer que seja o tipo de visão (respondente ou operante), é possível que a pessoa esteja "olhando para a multidão" sem que a esteja vendo, ou seja, ela está exposta ao estímulo eliciador, mas como seu sistema visual está "ocupado", por exemplo, com uma visão operante (a pessoa está lembrando visualmente de algum evento), a resposta visual não pode ser eliciada.

Geralmente essa discrepância entre olhar e ver é atribuída a uma falta de atenção. "Atentar" pode ser interpretado,

10 Skinner (1953/1966; 1974) não diferencia intenção de propósito. Tal diferenciação pode ser encontrada em Ryle (1949/1980). A distinção feita por esse autor não fere os princípios do behaviorismo radical. Entretanto, entendemos que essa discussão não faz parte dos objetivos desse trabalho, e por esse motivo não será explorada aqui. Optamos por manter a posição de Skinner e usar intenção e propósito como sinônimos. na maioria das vezes, como um comportamento precorrente que tem por objetivo tornar o controle de estímulos mais eficaz. Na visão condicionada quando alguém olha em determinada direção "procurando" uma pessoa ou qualquer outra coisa, esse comportamento (olhar) pode ser um precorrente para o comportamento de ver. O mesmo ocorre quando os dedos são passados sobre uma superfície com o intuito de descobrir sua textura, pois ao se fazer isso, uma resposta tátil é eliciada. Se o comportamento perceptivo em questão for auto-reforçador - se os estímulos produzidos pela resposta perceptiva têm função reforçadora -, seus precorrentes, entre eles a atenção, podem ser reforçados por ele. A atenção também é fundamental para a emissão de respostas visuais operantes durante o processo de resolução de problemas, se uma pessoa não se "concentra" no problema e fica pensando (ou com a atenção) em outras coisas, a produção de respostas visuais desejadas torna-se muito improvável.

\section{Comportamento Verbal, Consciência e Comportamento Perceptivo}

Como é possível interpretar a frase "eu estou vendo uma caneta"? Muitas vezes isso é compreendido como uma resposta a um estímulo visual (a caneta), entretanto, se fosse verdade, o que explicaria a ocorrência dessa mesma frase na ausência de qualquer caneta? Nesse momento a teoria da cópia passa a ser empregada e a frase refere-se a uma representação mental da caneta. Como já mencionado essas concepções são equivocadas da perspectiva de uma análise skinneriana. Resta agora explicar com mais detalhes o controle sob o qual está a resposta verbal "eu estou vendo uma caneta", tanto na presença, quanto na ausência do objeto.

Quando estamos diante de uma caneta e dizemos "eu estou vendo uma caneta", essa resposta verbal (tacto) refere-se à reação (resposta visual respondente) ao estímulo caneta e não ao próprio estímulo ${ }^{11}$. Para compreender essa passagem deve-se considerar que as respostas produzem estímulos (auto-estimulação) ${ }^{12}$, e quando se diz que a resposta verbal refere-se à reação, estamos na verdade dizendo que a auto-estimulação desempenha uma função discriminativa para a resposta verbal. Como já foi dito, nesse caso a "reação" é um comportamento respondente e, salvo em ocasiões especiais, na presença do estímulo visual a resposta visual é eliciada. Portanto, a comunidade verbal reforça o falante que relata a visão de uma caneta presente, quando ela também é vista pela comunidade. Fica claro que para responder discriminativamente ao próprio comportamento a pessoa necessita da ajuda de outras pessoas, de onde se conclui que a consciência é verbal e por esse motivo social. Mas, como a

11 Nesse sentido é possível concluir que a existência de um "estímulo em si" é uma inferência, pois o contato com ele se dá de modo indireto (é mediado pelo comportamento).

12 Isso pode ser verificado de forma explícita em Skinner (1957): "um falante usualmente ouve a si próprio e, assim, se estimula verbalmente...” (p. 64), mais adiante aparece outra citação referente a esse assunto: "na melhor das hipóteses podemos dizer é que a autoestimulação resultante de um resposta...” (p. 59). 
comunidade faz para reforçar ou não a resposta verbal que ocorre na ausência do estímulo? Ou melhor, como uma pessoa aprende a responder discriminativamente, de modo verbal, ao comportamento perceptivo encoberto, se a comunidade não tem acesso a ele?

A resposta é relativamente simples. Conforme apontado acima, a resposta verbal discriminativa é aprendida pelo sujeito sem que haja inferência ${ }^{13}$ por parte da comunidade, tanto a comunidade quanto o falante estão expostos ao estímulo visual. Como também já foi mencionado, a resposta visual tem como produto estímulos que auto-estimulam o sujeito; durante o processo de ensino pela comunidade esses estímulos podem adquirir algum controle sobre a resposta verbal, e quando a resposta visual regride para o nível encoberto (é emitida na ausência do objeto) a resposta verbal pode passar a ser totalmente controlada por esses estímulos.

Concluindo essa discussão é possível afirmar que, primeiro, "ter consciência do próprio comportamento", no behaviorismo radical, significa emitir uma resposta verbal característica, um tacto, a um estímulo não verbal que é produto de uma resposta. Sendo assim, quando alguém relata estar vendo um objeto, essa pessoa está relatando seu comportamento perceptivo e não o objeto propriamente dito. Uma vez que a contingência entre tacto e estímulo tactado é estabelecida pela comunidade verbal, conclui-se que a consciência é social. Segundo, o comportamento perceptivo, assim como qualquer outro comportamento, pode ser emitido tanto com autoconhecimento, como sem autoconhecimento (Skinner, 1974). A diferença é que no primeiro caso há a emissão de uma resposta verbal discriminativa (tacto), e isso quer dizer que a resposta verbal não é fundamental para que o sujeito possa ver, mas sim para que ele tenha consciência disso.

\section{Pensamento e Comportamento Perceptivo}

Tradicionalmente, o pensamento é tratado como uma atividade "cognitiva" obscura que possui uma natureza especial, tornando-se, por esse motivo, inacessível ao estudo objetivo (Ryle, 1949/1980; Skinner, 1957, 1968, 1977/1982). Existem algumas possibilidades de desvendar o "pensamento", ou seja, de descobrir o que significa essa atividade "cognitiva".

O pensamento pode ser interpretado como comportamento. "Pensar muitas vezes é sinônimo de comportar-se" (Skinner, 1968, p.119), ou refere-se a processos comportamentais, isto é, a mudanças no comportamento como aprendizagem, discriminação, generalização e abstração.

13 Skinner (1945/1961) aponta para esse fato, mas, no entanto, há pelo menos uma inferência nesse processo: a de que o falante apresenta uma resposta visual similar à da comunidade. Essa inferência inicial parece ser passível de comprovação, pois se houvesse diferença significativa a comunidade não seria capaz de ensinar ao falante com sucesso, como por exemplo no caso dos daltônicos.
A relação do pensamento com o comportamento perceptivo pode ser encontrada no estudo da resolução de problemas. Quando se resolve um problema de modo encoberto, o pensamento, na maioria das vezes, é "invocado" como um meio de explicação para os "processos cognitivos" envolvidos. Na verdade, boa parte do que é descrito como pensamento na resolução de problemas refere-se a comportamento perceptivo encoberto.

Inicialmente parece ser importante explicar, aqui, porque o comportamento regride para o nível privado, porque deixa de ocorrer de modo aberto, uma vez que praticamente todo comportamento tem sua emissão original no nível publico, incluindo o comportamento perceptivo (Skinner, 1953/ 1966, 1957, 1968; 1969). Existem pelo menos três possibilidades do comportamento tornar-se encoberto: (1) quando o controle de estímulos é fraco ou envolve punição; (2) quando ele é reforçado automaticamente; (3) quando se trata de um precorrente, e tem, portanto, apenas a função de tornar o comportamento subseqüente mais eficaz (Skinner, 1968).

O comportamento perceptivo pode regredir ao nível encoberto por qualquer um dos motivos citados acima: quando alguém é punido por olhar para um material pornográfico, se essa visão for suficientemente reforçadora, ele pode ver tais cenas sem a necessidade de estímulos específicos; mesmo quando não há punição, dado um nível de privação, isso ainda pode acontecer; na resolução do problema do cubo, descrito anteriormente, se o comportamento perceptivo, que nesse caso tem função de precorrente, não regredisse ao nível encoberto e, portanto, não pudesse ser emitido, para resolver o problema de modo visual seria preciso ter um cubo nas mãos, pintar suas faces, cortá-lo e assim por diante.

Uma vez que o comportamento regride ao nível encoberto ele torna-se diretamente inacessível para outras pessoas, fato esse que, na maioria das vezes, justifica chamá-lo de pensamento e a partir disso passar a considerá-lo como um evento de natureza especial. Isso não ocorreria se todo o processo fosse observado e se o observador conhecesse as relações funcionais envolvidas, pois em termos funcionais não há diferença entre um comportamento encoberto e um comportamento manifesto, ambos são mantidos por variáveis passíveis de ser manipuladas. Nesse sentido, se é possível estudar de modo científico o comportamento manifesto, o mesmo pode ser dito do comportamento encoberto.

Por fim, a crítica que se extrai dessa análise é que as abordagens mentalistas cometem o erro de localizar o pensamento na mente. Fazendo-se isso os "conteúdos mentais" tornam-se inacessíveis para um estudo objetivo. A proposta aqui defendida é que o pensamento pode ser interpretado em termos de comportamento e processos comportamentais, não importando se são públicos ou privados, pois não diferem no que diz respeito à sua natureza devendo ser tratados da mesma maneira. A possibilidade de interpretação do "pensamento" como comportamento perceptivo encoberto é um dado que vem corroborar essa perspectiva, embora, naturalmente, o conceito de pensamento envolva outros tipos de comportamentos precorrentes, como, por exemplo, memorizar e criar (Skinner, 1968, 1974). 


\section{Comportamento Perceptivo e Explicação Causal do Comportamento}

A questão da "causalidade" é um assunto controverso dentro da teoria skinneriana, principalmente quando se trata de eventos privados. Algumas considerações feitas por Skinner (1953/1966), tais como, "as emoções não são causas", "a ansiedade não é causa", acabam por dar margem a uma interpretação epifenomenalista dos eventos privados no behaviorismo radical. O presente trabalho não concorda com esse tipo de interpretação, pois defende que os eventos privados têm função em uma cadeia comportamental, quando passam pelo comportamento verbal, e talvez mesmo quando isso não ocorra. Essa segunda hipótese será explorada adiante usando como exemplo o comportamento perceptivo.

Para analisar a causalidade no comportamento perceptivo faz-se necessário o uso de exemplos de encadeamento comportamental. Já se discutiu anteriormente os "tipos" de comportamento perceptivo (respondente, operante), assim como seus níveis (aberto e encoberto), portanto, aqui não serão apresentados muitos detalhes a esse respeito, recorrendo-se a essas distinções apenas quando a diferenciação mostrar-se indispensável no que diz respeito à explicação causal.

De modo geral, o comportamento perceptivo aberto consiste em uma resposta perceptiva (visual, olfativa, etc.) eliciada por um estímulo visual, olfativo, etc. A partir desse comportamento é possível "caminhar" pela cadeia tanto no sentido de buscar os comportamentos anteriores quanto os posteriores. Nos antecedentes (ou precorrentes) encontramse os comportamentos denominados como "atenção" - comportamentos que têm por função tornar a estimulação mais ou menos eficaz - e o "propósito" - as causas do comportamento, que têm a função de indicar a direcionalidade da seqüência comportamental. A relação entre esses precorrentes é evidente, a história de reforçamento "dirige" a atenção do indivíduo (estabelece um propósito), aumentando a probabilidade, no caso do comportamento perceptivo, de que determinado objeto seja visto. No entanto, pode haver o caso em que a atenção à determinado objeto impeça que estímulos relevantes sejam vistos; quando isso ocorre diz-se, freqüentemente, que a pessoa estava distraída. Conclui-se, portanto, que a relação entre "atenção" e "propósito" é complexa: o propósito pode determinar a atenção do mesmo modo que a atenção pode determinar o propósito, em outras palavras, atentamos a algo porque isso produziu uma conseqüência reforçadora no passado, mas é possível também que por estarmos atentos a determinado objeto (pensando visualmente em alguém ou em alguma situação específica), não sejamos capazes de ver algo que está "diante de nossos olhos".

Já partindo do comportamento perceptivo e indo na direção dos comportamentos posteriores, encontram-se, na maioria das vezes, outros comportamentos que culminam em uma conseqüência que vai controlar toda a cadeia comportamental. Se a conseqüência for reforçadora, toda a cadeia será reforçada e o "propósito", dada as circunstâncias propí- cias, será engajar-se novamente no comportamento perceptivo que produziu os subseqüentes que culminaram nessa conseqüência. Se a conseqüência for punitiva, ocorrerá o efeito oposto, ao invés de "atentar" o sujeito passará a evitar o comportamento perceptivo responsável pela conseqüência. Sendo assim, os comportamentos que evitarem essa conseqüência serão selecionados por reforçamento negativo.

Outra possibilidade é a de que o comportamento perceptivo apareça de modo encoberto; seria, por exemplo, o que ocorre quando o sujeito, sob forte privação, vê na ausência do estímulo visual. Com base no que foi dito anteriormente, quando, em uma cadeia comportamental, os estímulos produzidos por uma resposta visual têm função reforçadora, a emissão dessa resposta pode ocorrer na ausência do estímulo específico (visual, no caso da visão, auditivo, no caso da audição e assim por diante). Dessa forma, tanto estímulos que têm pouca semelhança com o estímulo específico, quanto estímulos irrelevantes podem ter função discriminativa para a emissão da resposta perceptiva. Nesse caso ocorreria uma exacerbação da "atenção" ao ponto das diferenças entre os estímulos tornarem-se irrelevantes.

A explicação aqui proposta defende que mesmo em casos muito simplificados, como, por exemplo, no processo de condicionamento pavloviano, o comportamento perceptivo desempenha um papel fundamental, embora, na maioria das vezes, isso seja desprezado nas explicações do comportamento. Para usar um exemplo clássico, o cão que salivava originalmente para comida na boca, através de condicionamento, passa a salivar para uma sineta. Uma possível explicação para isso é que um estímulo "gustativo" ou "apetitivo" (comida) elicia uma resposta gustativa que, através da produção de estímulos, auto-estimula o cão. Essa autoestimulação elicia a resposta de salivar. Depois do condicionamento um estímulo auditivo (sineta), originalmente neutro, passa a eliciar a resposta salivar; é possível que o que realmente esse estímulo elicie seja a resposta gustativa, que auto-estimula o cão, eliciando a resposta de salivar. Esse exemplo demonstra a possibilidade do comportamento perceptivo desempenhar um papel causal ${ }^{14}$, sem que para isso ocorra uma discriminação verbal por parte do sujeito.

Um exemplo mais complexo seria o que envolve o comportamento e condicionamento operantes. Um rato privado de comida é colocado em uma caixa com uma alavanca que acionada libera uma pelota de comida. A princípio, comportamentos característicos da espécie ${ }^{15}$ são emitidos na presença dos estímulos (visuais, táteis, olfativos, etc.) fornecidos pela situação experimental. Seguindo a interpretação proposta, estímulos da situação experimental eliciam respostas perceptivas que auto-estimulam o rato e "liberam"16 as respostas características. O comportamento de pressionar a alavanca pode demorar muito para ser emitido pela pri-

14 Obviamente, causalidade está sendo interpretada, aqui, como relação funcional, e o complexo conceito de encadeamento é de importância fundamental para essa análise.

15 Filogeneticamente selecionados (Skinner, 1969).

16 Ver The Phylogeny and Ontogeny of Behavior em Skinner, 1969. 
meira vez, sendo assim, o experimentador pode valer-se da modelagem, fazendo aproximações sucessivas, ou seja, reforçando, com pelotas de comida, comportamentos cada vez mais próximos do desejado (no caso pressionar a alavanca). A interpretação proposta seria que respostas perceptivas vão sendo selecionadas ou tornam-se relevantes, e os estímulos produzidos por essas respostas assumem a função de estímulos discriminativos para a resposta de pressão à alavanca. Dessa forma, em pouco tempo o rato estará pressionando a alavanca e tendo como conseqüência uma pelota de comida. Aí está o comportamento operante: na situação experimental o rato pressiona a alavanca e recebe uma pelota de comida. A interpretação proposta é a seguinte: os estímulos visuais, táteis, olfativos, etc. eliciam respostas perceptivas que têm função auto-estimuladora, tornando-se estímulos discriminativos para a emissão da resposta de pressão à barra. Assim, quando a resposta produz a conseqüência reforçadora (pelota de comida, que também funciona como estímulo que elicia uma resposta perceptiva gustativa), ela aumenta tanto a probabilidade de emissão da resposta na presença do estímulo discriminativo (estímulo produzido pela resposta auto-estimuladora, por exemplo, o estímulo produzido pela resposta visual "ver a barra", onde "barra" é usualmente considerado como um estímulo discriminativo), quanto a "atenção" aos estímulos eliciadores (os estímulos discriminativos usuais).

Uma explicação desse tipo, basicamente lógica e conceptual, esbarra em um problema. A análise do comportamento está fundamentada no princípio de manipulação de variáveis bem como visa a previsão e controle do comportamento. Portanto, uma análise como a proposta acima, só atingirá seus objetivos se for possível, de alguma maneira, manipular as variáveis, sejam elas públicas ou privadas, envolvidas. Dessa forma, essa explicação cria um problema de pesquisa para a ciência do comportamento, isolar as variáveis privadas, que nesse caso são os estímulos com função autoestimuladora, e demonstrar se, além de lógica, também é empiricamente possível provar que elas controlam o comportamento. Apenas a partir de resultados de pesquisas dessa natureza poder-se-á confirmar ou refutar essa explicação.

O ponto de vista defendido, aqui, é o de que o comportamento perceptivo, embora envolva respostas privadas, desempenha papel causal, ou seja pode ter função na determinação de outros comportamentos, contrariando assim interpretações epifenomenalistas da obra de Skinner (como, por exemplo, a de Creel, 1980).

\section{Conclusão}

Com base no que foi dito é possível afirmar que as variáveis determinantes da percepção passam pelo menos por quatro tópicos: propósito, atenção, consciência, e pensamento $0^{17}$.

17 Pensamento é um tema complexo na obra skinneriana, podendo ser considerado como um comportamento precorrente para a resposta
O propósito, que no behaviorismo radical pode ser interpretado em termos de reforço e operações estabelecedoras, diz respeito ao porque da emissão de determinado comportamento, ou seja, na percepção, o motivo pelo qual se vê, ouve, etc. determinadas coisas e não outras. O que está realmente envolvido nesse motivo são as variáveis motivacionais (privação e estimulação aversiva), emocionais, as contingências de reforço, e a herança da espécie que se combinam entre si e produzem as sensações de ver, ouvir, etc. O produto dessa combinação é verificado em alguns lapsos na percepção como quando um ruído é ouvido por uma pessoa que está esperando visitas, como alguém que bate à sua porta, ou quando o homem apaixonado vê a sua amada em uma mulher que não conhece (Skinner, 1953/1966).

Com relação à atenção basta apenas observar, aqui, como já foi dito anteriormente, que o propósito é um precorrente desse comportamento, ou seja, por exemplo, quando alguém "olha na direção de...", o olhar está controlado por um propósito. Por sua vez, "olhar na direção de...", como comportamento de prestar atenção, é um precorrente que contribui para clarificar estímulos que são importantes no controle do comportamento perceptivo.

A consciência relaciona-se com a percepção da seguinte forma: tem-se consciência do comportamento perceptivo quando uma resposta verbal discriminativa (tacto) é função de um estímulo produzido pela resposta perceptiva. Sendo assim a consciência, o tacto, descreve a resposta perceptiva, o que permite determiná-la com mais adequação.

Quando se trata do pensamento remete-se a discussão, na maioria das vezes, ao comportamento encoberto. Tratase do comportamento perceptivo que, por se manifestar de maneira encoberta, passa a ser tratado como pensamento; entretanto, ele deve ser abordado do mesmo modo que na sua ocorrência pública. O pensamento (interpretado como comportamento perceptivo encoberto) está intimamente relacionado com o processo de resolução de problemas, pois trata-se de respostas privadas (geralmente visuais) que podem desempenhar a função de estímulos discriminativos (através da auto-estimulação) aumentando a probabilidade da resposta consumatória ser emitida. Esse tipo de análise, demonstra uma das possíveis implicações do estudo da percepção - a análise do processo de resolução de problemas.

Verifica-se, portanto, que uma teoria da percepção que se embasa nos preceitos do behaviorismo radical tem várias vantagens em relação à teoria da cópia, a principal é que a identificação de variáveis determinantes da percepção, mesmo que muitas vezes privadas, torna o assunto parte do cam-

consumatória no processo de resolução de problemas. Partindo desse ponto de vista, pensar pode ser: intencionar, atentar, perceber, memorizar, criar e qualquer outro comportamento (ou processo comportamental) que seja capaz de tornar possível a solução de um problema. Portanto, o pensamento na obra de Skinner é um conceito que deve ser analisado em termos de seus mais variados usos. O presente trabalho analisou o pensamento apenas como perceber. No entanto, é possível analisar os precorrentes do comportamento perceptivo como pensamento, uma vez que intencionar, atentar e tomar consciência de... são precorrentes tanto de perceber quanto de pensar. 
po da ciência deixando para traz outros tipos de explicações que fazem uso da noção de "cópia". Além disso, a presente explicação mostra-se melhor porque, fazendo uso do comportamento perceptivo, deixa para trás outros problemas encontrados em explicações dualistas da percepção, como, por exemplo, a dicotomia experiência versus realidade enquanto nas teorias mentalistas da percepção a realidade não é diretamente conhecida pelo indivíduo (existe a mediação por parte da cópia), a teoria proposta por esse trabalho argumenta que a "experiência", no sentido usado pelas teorias dualistas, não existe, e tudo aquilo que afeta o organismo é realidade para ele.

Existe ainda uma grande falha nas teorias que fazem uso da cópia mental para explicar a percepção, elas não explicam a passagem da cópia para a percepção propriamente dita. Mesmo que fabriquemos uma cópia do mundo, ainda assim é preciso explicar como essa cópia é percebida. Nesse sentido o uso do controle de estímulos na explicação também se mostra mais vantajoso que a teoria da cópia.

Portanto, os dois problemas enfrentados para explicar a percepção parece que podem ser dissolvidos. Primeiro, quais são os determinantes da percepção - através da análise do comportamento perceptivo e das variáveis que o controlam é possível chegar a uma solução sem que para isso tenhamos que recorrer à noção de "experiência". Segundo, o que é determinado pela percepção. O presente estudo tentou dar uma possível resposta para esta questão através do estudo do comportamento perceptivo enquanto precorrente para a resolução de problemas.

\section{Referências}

Creel, R. (1980). Radical Epifenomenalism: B.F. Skinner's Account of Private Events. Behaviorism, 8, 31-53.
Köhler, W. (1970). Gestalt Psychology. New York: Liveright (Originalmente publicado em 1927).

Pavlov, I.P. (1960). Conditioned Reflexes. (G.V. Anrep, Trad.) New York: Dover Publications. (Trabalho original publicado em 1927)

Ryle, G. (1980). The Concept of Mind. New York: Penguin Books (Originalmente publicado em 1949).

Skinner, B.F. (1957). Verbal Behavior. New Jersey: Prentice-Hall.

Skinner, B.F. (1961). The Operational Analysis of Psychological Terms. Em: B.F. Skinner (Org.), Cumulative Record. New York: Appleton-Century-Crofts.

Skinner, B.F. (1966). Science and Human Behavior. New York: The Macmillan Company.

Skinner, B.F. (1968). The Technology of Teaching. New York: Appleton-Century-Crofts.

Skinner, B.F. (1969). Contingencies of Reinforcement: A Theoretical Analysis. New York: Appleton-Century-Crofts.

Skinner, B.F. (1974). About Behaviorism. New York: AppletonCentury-Crofts.

Skinner, B.F. (1982). Why I Am Not a Cognitive Psychologist. Em B.F. Skinner \& R. Epstein (Orgs.), Skinner for the Classroom (pp. 177-191). Illinois: Research Press.

Turing, A. (1996). Computação e Inteligência. (F. C. Hansem, Trad.) Em J. de F. Teixeira (Org.), Cérebros Máquinas e Consciência: Uma Introdução à Ciência da Mente. São Carlos: Editora da UFSCar. (Trabalho original publicado em 1950)

Watson, J.B. (1930). Behaviorism. Chicago: The University of Chicago Press. (Originalmente publicado em 1924) 